Volume 27, 2017

http://journals.sfu.ca/cjsdw

\title{
Comment
}

\section{Report from the Relaunch of the CJSDW/R}

\author{
Amanda Goldrick-Jones \\ Simon Fraser University
}

On November 17, 2016, the editors of the CJDSW/R hosted an event at the Simon Fraser University (SFU) Harbour Centre campus in Vancouver celebrating the relaunch of the journal. Attendees came from a variety of institutions across British Columbia, including SFU, the University of British Columbia (UBC), University of the Fraser Valley (UFV), Vancouver Island University, Emily Carr University of Art and Design, and Douglas College.

Co-editor Joel Heng Hartse opened the event by welcoming everyone and thanking SFU's Centre for Language Learning, Teaching, and Research (CELLTR) for supporting the event. Joel summarized the transfer of the CJSDW/R to SFU and shared the good news that, thanks to an SFU grant, the entire archive of older issues will be digitized and made accessible online. The journal will invite rolling submissions for publication, so issues are no longer dependent on having a certain number of articles.

Joel then introduced Dr. Ling Shi of UBC's Department of Language and Literacy Education, featured speaker on "Paraphrasing in Academic Writing by L1 and L2 Writers."

Dr. Shi presented some of her recent work on paraphrasing, which she described as very complex and often elusive, especially for L2 writers. She presented two different views of paraphrasing:

1. Restating source text accurately with a credit to the author, an approach suggesting that the paraphrase should be logically equivalent but with different wording. This can become a decontextualized linguistic exercise (especially for EAP contexts), which could be good for improving linguistic proficiency. But students may fail to see the rhetorical value of paraphrasing with this approach; they do not see it as a meaning-making process. Some students may therefore choose quoting instead of paraphrasing. 
Volume 27, 2017

http://journals.sfu.ca/cjsdw

2. Good paraphrasing involves interpretation or inferential thinking, making a conclusion based on statements or noticing similarities. This encompasses the second view of paraphrasing-interweaving and integrating source material with one's own authorial intention for knowledge transformation and critical thinking.

Dr. Shi then presented data about students' writing of disciplinary research papers:

1. Students paraphrase with a lot of copying and claim they cannot change any words in the paraphrase because of a concern for accuracy of meaning. This is not an issue of linguistic proficiency because both L2 and L1 writers have expressed the same concern.

2. Students paraphrase with substantial linguistic adaptation and view paraphrasing as a meaning-making process, through which they re-contextualize the source information in their own writing.

3. Students paraphrase by choosing certain information from the source text and view paraphrasing as a means of directing readers' attention to their own writing.

4. Students paraphrase based on their inferential thinking or interpretation of the source text.

5. Students also paraphrase to evaluate the source text by indicating disagreement with the original author. However, by citing the original source, the student writers are sometimes not aware that they have misattributed their own ideas to the original author.

In Dr. Shi's view, good paraphrasing depends on having read and understood the texts, and being able to filter the information and recount only those relevant elements. The linguistic adaption of the paraphrase is a by-product of this meaning-making process involving one's own inferential thinking. As a means to express one's own thinking, paraphrasing is thus linked to students' learning of content knowledge in their disciplinary areas.

The second part of the event was a panel discussion on the future of writing centres in Canada featuring Heather Fitzgerald of Emily Carr University of Art and Design, Dana Landry of UFV, and Cecil Klassen of Douglas College, who were introduced by the journal's other coeditor, Sibo Chen. The three speakers chose to organize their comments into three different topics: advocacy and funding, multilingual/international students, and professional organizations of writing studies in Canada. 
Volume 27, 2017

http://journals.sfu.ca/cjsdw

\section{Topic 1: Advocacy and Funding}

Writing centres may seem stable, but even with all the right support systems seemingly in place, top-down changes may be implemented without consulting writing centre staff. Dana described how UFV replaced the writing centre with a learning centre. The case of Douglas College was also mentioned, where the learning centre was moved into the library. What can we do when established writing centres can vanish virtually overnight? How can we communicate the scholarly work of writing centres to counter misrepresentations and avoid being re-formed by administrators? On another note, writing centres in small colleges with little institutional support may experience boundary creep (trying to do everything) in an attempt to justify continued funding.

\section{Topic 2: Multilingual/International Students}

Traditionally multilingual students are often seen as heavy users of writing centres, disproportionally using writing centre services relative to L1 peers. Is this true, though? Emily Carr University conducted research into this question and found that $57-87 \%$ of Foundation (first year) students identified themselves as multilingual. Similarly, 55-70\% of writing centre users identified themselves as multilingual. So, in this regard, writing centres may be reflective of the trends prevailing across larger institutions. This also has implications for peer-tutor training, which traditionally assumes clients are native speakers.

Writing centres also tend not to highlight the skills that multilingual students bring; rather, these centres may struggle with "deficit" or "remedial" discourses around students for whom English is an additional language. It may be necessary to change the criteria by which faculty discuss student writing and not separate multilingual students so much, but rather unify student experiences.

Tutors regularly say they don't know how to help second language writers with grammar questions. Tutors can be trained, but sometimes more expertise is needed. A mixed training model may be needed, blending peers with professionals and/or faculty who have training in second language pedagogy. To support multilingual students, writing centres should perhaps expand their mission beyond a focus on student academic papers (which privileges monolingual English speaking students) to include other forms of academic oral and written communication such as effective reading, presentation, discussion, and note-taking skills. 
Volume 27, 2017

http://journals.sfu.ca/cjsdw

\section{Topic 3: Tapping More into Various Professional Organizations.}

Writing centres in Canada need to become more organized and networked and think about relationships between organizations. This has implications for how writing centre staff think of themselves and/or depict themselves within institutions. It is possible to redefine writing centres' presence through advocacy backed with research. One challenge for writing centres is to explore whether one organization can represent all configurations of writing support, as well keep conversations going across organizations.

Joel thanked all participants and invited everyone to spread the word about the re-launched journal, and to consider submitting articles. 